\title{
Library-Led Forums on Broadband: An Inquiry into Public Deliberation
}

\author{
Donna Schenck-Hamlin, Soo-Hye Han, and Bill Schenck-Hamlin
}

\begin{abstract}
Access to high-speed (broadband) Internet in public libraries requires a well-informed public to advocate, particularly in periods of government funding reductions and rapid technical and regulatory change. Libraries are encouraged by the National Broadband Plan to facilitate public inquiry on this issue by holding participatory forums. To collect evidence of the potential public response to library-led forums on this topic using a deliberative protocol, researchers conducted pre- and postforum surveys and content-analyzed recorded transcripts from thirteen library forums in north central Kansas. Results show positive influences of deliberation on participants' information seeking, political self-efficacy, subsequent issue advocacy, and general satisfaction with the forum experience.
\end{abstract}

L

ibrarians considering a stronger role in engaging public issues are seeking to deepen the civic impact of their institutions. Given their position as places of community learning and their standards of equal access to information, public libraries have traditionally played host to annual civic events spotlighting critical current issues. But providing space for public events is only the baseline for a recent movement by many librarians toward greater leadership in civic dialogue and deliberation. Concern with increasing social and political polarization and its impact on civic decision making has inspired many to reassert their role in promoting participatory democracy by an informed public. ${ }^{1}$

Public issues are by nature contentious and complex, featuring multiple stakeholders, competing values, and topical knowledge beyond the immediate experience of many citizens. Today's libraries offer information-seeking tools, access to online resources, and research assistance to help patrons locate and read (or view, or listen to) an enlarged universe of information on any public issue. Private reading alone, however, does not constitute public engagement,

This research was enabled with grants from the Bill and Melinda Gates Foundation to the State Library of Kansas and from the Kansas State University College of Arts and Sciences Faculty Enhancement Program. Support for the library forums was provided by Kansas State University's Institute for Civic Discourse and Democracy (http://icdd.k-state.edu).

1. Many examples of libraries assuming this role can be found in the American Library Association's partnership with the Harwood Institute in the "Promise of Libraries Transforming Communities" initiative (http://www.ala.org /transforminglibraries/libraries-transforming-communities) and in the ALA Center for Civic Life (http://discuss.ala.org /civicengagement/).

Library Quarterly: Information, Community, Policy, vol. 84, no. 3, pp. 278-293. (c) 2014 by The University of Chicago. All rights reserved. $0024-2519 / 2014 / 8403-0003 \$ 10.00$

278 
although it can contribute to better-informed community discussion and problem solving. Making libraries the home to community issue conversations is an essential addition to their role in facilitating public inquiry.

Dialogue and deliberation as modes of civic engagement have been developed and promoted over the past three decades with increasing specificity, giving librarians a rich range of tools and organizations available to assist them. These resources have been collected and tested by professional practitioners in networks such as the National Coalition for Dialogue and Deliberation (NCDD) and the International Association for Public Participation (IAPP). Interdisciplinary scholars in a field known as "deliberative democracy" theorize that practices of deliberation and dialogue may strengthen citizens' engagement with social and political processes of self-governance, with the potential of strengthening electoral democracy (Gastil and Levine 2005). Evidence for these claims is being actively sought by researchers who investigate the dynamics of citizen deliberation in various controlled experiments or from observations of planned public events. ${ }^{2}$

\section{Background and Literature Review}

Professionals from the fields of librarianship and communication studies joined together in 2012 to collect such evidence from library-led forums on a complex issue, that of high-speed (i.e., broadband) Internet access, in rural north central Kansas. The issue, not featured frequently in headlines or sound bytes revealing political biases, was unlikely to be associated with national controversy. However, the future implementation of policy choices regarding high-speed Internet does have demonstrable impact on rural public libraries and their users in both the private and public sectors.

This makes broadband a useful current public issue for examining the impacts of facilitated discussion in libraries on participants' information seeking on the issue; additional discussion and advocacy of the issue; self-efficacy or confidence in their ability to engage on the issue; and satisfaction with the public discussion experience, which affects their inclination to engage again. While the literature often reports on public engagement methods of libraries regarding their own policies (Alita 2001), the authors found no library research that scrutinized specific impacts of library-led deliberation on the above participant attributes. Research that can demonstrate these impacts from library-led public forums will help librarians be better prepared, as Paul T. Jaeger, John Carlo Bertot, and Ursula Gorham (2013) suggest, to advocate in the political and policy-making process.

2. Although many definitions of "deliberation" have been offered in this context, this study relies on a framework specifying face-to-face public deliberation as " $(a)$ a process that involves the careful weighing of information and views, (b) an egalitarian process with adequate speaking opportunities and attentive listening by participants, and (c) dialogue that bridges differences among participants' diverse ways of speaking and knowing" (Burkhalter, Gastil, and Kelshaw 2002, 418). 
Despite society's dependence on broadband access for communication, information, and other vital transactions, public understanding or advocacy for universal Internet access is low in the United States (Falch 2007, 254). This should not be surprising, given the complexity of telecommunications regulation. Although most consumers may not inspect their phone bills for the surcharge supplying universal service funds (USF), this mode of support for universal access is well known to public libraries, which employ USF for E-rate discounts to serve low-income populated regions. ${ }^{3}$ Public libraries have been found to be the "first and last" resort for Internet access for those unable to afford high-speed connections at home (Bertot 2006, 17). Among US Internet users without a computer at home, 32 percent reported using a public library for access in 2011 (US Department of Commerce 2013, 35). Libraries are taking the lead in addressing a growing digital divide between high- and low-income consumers and between high-population urban areas with a concentration of Internet service providers (ISPs) and low-population rural areas considered too "high cost" to merit commercial ISP investment.

The 2010 National Broadband Plan by the Federal Communications Commission aimed to update USF funding formulas based on "plain old telephone service" to include broadband, supporting upgrades to speeds now demanded by an explosion of online applications that supplanted print-based or face-to-face processes (Federal Communications Commission 2010). Ambivalence, uncertainty, or ignorance of universal access principles and mechanisms can slow the spread of connectivity, especially in a climate of budget stalemates and reductions.

In order to stimulate discussion and learning about broadband access by citizens themselves, thirteen libraries in a rural regional library network organized public forums in the spring of 2012. The Broadband Everywhere forums project employed facilitated discussion as the format for the events, in order to elicit public inquiry into the means - public and private, from local to national — of achieving specific broadband access speeds for all citizens, consistent with the terms of universal access. Significantly, the forums were held during a 2012 state legislative session in which bills were proposed to eliminate one means by which public libraries receive subsidized access.

Thirteen public librarians convened forums in a Kansas rural region characterized by a lowdensity, ethnically homogeneous, and aging population in twelve contiguous counties of one state. The librarians had previously attended a fall 2011 training workshop on broadband advocacy by the State Library of Kansas and training in facilitation by a Kansas State University faculty facilitator who also assisted in developing the events' protocol and publicity.

The libraries solicited participants with a press release titled "Town Hall Meeting to Discuss Broadband Internet Access" distributed to local newspapers, library patrons, on their website (and including social networking sites, e.g., Facebook), and at local chambers of

3. See http://www.fcc.gov/encyclopedia/e-rate-schools-libraries-usf-program. 
commerce and schools. ${ }^{4}$ Scheduled between February and April 2012, the events began at 6:30 p.m. and lasted about two hours. Free pizza was served as an incentive to attend the evening forums. Upon arrival, participants were informed of researchers' interest in gathering data from the forums, and their permission was obtained to answer surveys and have their conversations anonymously recorded for research. Then they were given a discussion guide linked to a website with more information (see Schenck-Hamlin, Barta, and Burgess [2010] for a blind review). The event outline is provided in table 1.

As a collaboration between public libraries and university researchers, the Broadband Everywhere forums project, initially conceived to promote public awareness, offered an opportunity to analyze data from participants in deliberation. Often such opportunities are missed, as forum organizers focus on the delivery of their events with only cursory feedback surveys to gauge their success. Thanks to previous facilitated forum interactions, the Kansas State University faculty and North Central Kansas Libraries system leaders shared an interest in addressing prevailing research questions about public participation itself through deliberation. Because the forums featured open public meetings, the researchers were unable to design an experiment with control and treatment groups. However, as a case study, the data gathered could help to answer research questions about information seeking, self-efficacy, and participant responses to deliberation on the broadband access issue.

During public discussions, the need for information is frequently expressed through questions and answers but at a rapid rate that does not allow for a detour to catalogs or databases. The content of those interactions is rich with the topics patrons need to explore within an issue. Content analysis of forum transcripts could provide libraries with the topics for subsequent information development and delivery to their patrons. In addition, librarians investing their resources in deliberative events are eager to learn whether the public discussion results in participants seeking more information on the topic afterward, and by what route.

Libraries, or any groups hosting public forums, would profit by learning whether participants follow up a deliberative event with additional conversations and with whom besides the other event participants. Deliberative forums serve to engage nonelected citizens in collective policy exploration, though participants may individually be motivated to influence policy choices of elected officials by means of public hearings, petitions, letters, and other forms of persuasion. Some forum protocols actually require participants to formulate a consensus position that is forwarded to elected officials as another means of gauging their public's opinion on the issue. While this project did not involve such group decision making, the influence of

4. Text of solicitation: "Communities thrive, grow and attract and retain businesses when broadband access is supported. Investment in access increases the capacity of communities to build on their economic base and strengthen tax revenues. Libraries are part of this solution, providing access to computers and broadband connections for all members of the community. Please join your neighbors and fellow citizens for an evening of discussion on how broadband access affects your community. [local time/date/location details] A light supper will be served followed by discussion." 
Table 1. Outline of Broadband Everywhere Forums

1) Introduction by the lead moderator

a) Summary of reasons for addressing broadband access

b) Six-minute video of commentary on the importance of broadband by three stakeholdersregional ISP, business owner, and educator

c) Review and approval of ground rules for deliberation*

d) Grouping of participants to tables of three to eight people (average group $=$ six, excluding tabletop facilitators and note takers)

2) Facilitated table discussions averaging sixty-five minutes, led by protocol questions

a) Issue stake - asking participants to describe their own and their community's current and future anticipated Internet use

b) Issue orientation - asking participants to describe Internet access along a value-oriented continuum, e.g., "right," "public utility," "service," "pay-to-play"

c) Alternatives exploration - examining four funding sources for broadband access and value orientations to them: federal, state, municipal, and private

d) Issue involvement - asking participants what would have to happen and what they are willing to do to influence decision makers

3) Table facilitator reports of group ideas to the larger forum and summary by lead moderator

* (1) Seek understanding and common ground, (2) expect and explore conflicting viewpoints, (3) give everyone opportunity to speak, (4) listen respectfully and thoughtfully, (5) appreciate communication differences, (6) stay focused on issues, and (7) respect time limits.

the forums on each participant's subsequent discussion and advocacy on the issue could be collected in postforum surveys.

Not every participant enters or leaves a forum feeling that he or she is able to pursue a set of actions or preferences on the issue. This self-perception, known as "self-efficacy," is examined by deliberative democracy researchers exploring the contribution of public discussion to individuals' self-confidence in policy arenas. Bandura $(1995,2)$ articulated the foundation of self-efficacy theory, based on "belief in one's capabilities to organize and execute the course of actions required to manage prospective situations.” Self-efficacy research has been undertaken by many disciplines, including library and information science (Kurbanoglu 2003; Bronstein and Tsivian 2013), to determine its relationship to performance and to identify sources of selfefficacy beliefs that might be used to contribute to successful behaviors in specific domains. Scholars in the field of political science have explored the domain of political engagement, specifying internal political self-efficacy as "citizens' feelings of their own personal competence to participate in politics" (Morrell 2005, 50). Facilitated public deliberation, conducted according to a set of normative standards, has been associated with, but not conclusively shown to influence, participants' political efficacy (Gastil 2004, 326). The broadband forums could offer evidence to bear on this inquiry.

Researchers on deliberative democracy have outlined the parameters of participants' satisfaction with the experience. Jennifer Stromer-Galley and Peter Muhlberger (2009) examined 
participants' willingness to work with the same group in the future, desire to participate in another deliberation, and their perception that the process caused them to reevaluate prior assumptions. They found that satisfaction with the deliberative process contributes greatly to a person's motivation to participate in the future (Stromer-Galley and Muhlberger 2009, 187). If the libraries obtained evidence of high satisfaction from citizens' experience of their forums, then deliberation to promote broadband engagement would be validated.

\section{Research Questions}

The research questions about information seeking, self-efficacy, and participant responses to deliberation on the broadband access issue are listed here.

RQ1a. What information needs of participants are exposed through deliberation on broadband?

RQ1b. Does participation in deliberation prompt information seeking after the event?

RQ1C. Does participation in deliberation prompt additional discussion and advocacy on the issue after the event?

RQ2. Does participants' self-efficacy on the issue of broadband access increase after deliberation?

RQ3. Do participants perceive the experience of deliberation to be satisfying?

\section{Method}

\section{Participants}

One hundred and forty-two participants volunteered to attend the public forums. They were divided into twenty-five small discussion groups spread over the thirteen public library forums. Researchers compared demographic data of participants with that of the twelvecounty rural region, as reported in the census. Of those who chose to attend, over half were female (56.3 percent), and most of the participants identified themselves as Caucasian (93.4 percent). The age of those who attended the forums was older $(M=56.5, \mathrm{SD}=14.8$, range $=$ 18-94 years of age) than the median average age of 39.7 for the twelve-county region in the census, and 73.5 percent reported having bachelor's degrees compared with 21.7 percent recorded in the census.

\section{Forum Content Analysis}

Of the twenty-five tabletop discussions, twenty-three were successfully audiorecoded, transcribed, and content analyzed by the researchers to examine information seeking by means of participant questions during the forums. The unit of analysis was an "utterance," defined as one individual's sequence of words during a deliberation until the next individual begins. Utterances coded as questions were classified as one of the following types: 
- Question based on a fact, e.g., What is your download speed?

- Question about value, e.g., Do you like your wireless service?

- Question about a proposal, e.g., Should we have municipal broadband?

- Question to clarify a previous statement, e.g., Did you mean ... ?

- Question not requiring an answer (rhetorical), e.g., Who would think ... ?

The five-person research team worked together to test and refine these definitions to ensure the reliability of coding. Five coders worked independently on different sets of the twentythree forum transcripts, always with two coders coding the same transcript. Intercoder reliability statistics showed acceptable agreements between the two coders (Cohen's kappa $=.93$ ).

\section{Surveys}

In addition to content analysis of the transcribed discussions, researchers employed surveys of the participants: a pretest survey on arrival at the event; an experience satisfaction survey at the end of the event; and a posttest survey sent by e-mail to those providing their e-mail addresses one month after the event. Up to two follow-up e-mails were sent if participants failed to respond to the first e-mail solicitation. The pre- and posttest surveys addressed selfefficacy before and after deliberation, and, in addition, the e-mailed survey addressed activities undertaken in the aftermath of the event.

Participants' self-efficacy was measured in the pre- and posttests by five items using a seven-point Likert scale ranging from strongly disagree to strongly agree (Cronbach's alpha $=.87$; see table 2 for the exact wording of the items). The first four items were adapted from widely employed measures of political efficacy introduced in the 1988 National Election Study (Niemi, Craig and Mattei 1991). The fifth was adapted from a measure in the original Center for Political Studies/National Election Study time series (Miller 1989).

To examine participants' perceived satisfaction with the forums, a five-point Likert scale ranging from strongly disagree to strongly agree was administered, employing eleven measures grouped into five dimensions: mutual respect, diversity of contribution, reevaluation, commitment to continued deliberation, and utility of deliberation (see table 3 for the exact wording of the items). Many items were adapted from Stromer-Galley and Muhlberger (2009) and Morrell (2010).

Activities related to information seeking to be reported were divided into three categories: information seeking, follow-up discussion, and advocacy (see table 4). Information-seeking activities included rereading the forum discussion guide, looking up the featured online broadband information guide, asking at the library for a printed version of the online information guide, and looking up other information from the Internet. Follow-up discussion activities included talking with friends and family about the issue, talking with community leaders about the issue, and talking with an Internet service provider. Advocacy activities included 
Table 2. Self-Efficacy Mean Scores from Pre- and Postforum*

\begin{tabular}{lcc}
\hline Item and Statement & $\begin{array}{c}\text { Preforum } \\
\text { Mean }\end{array}$ & $\begin{array}{c}\text { Postforum } \\
\text { Mean }\end{array}$ \\
\hline $\begin{array}{l}\text { I feel that I have a pretty good understanding of the important } \\
\text { issues facing broadband Internet access in our community }\end{array}$ & 4.12 & 5.35 \\
$\begin{array}{l}\text { I think that I am better informed about the issue of broadband } \\
\text { Internet access in our community than most people }\end{array}$ & 4.09 \\
$\begin{array}{l}\text { Sometimes the issue of broadband access seems so complicated } \\
\text { that a person like me can't really understand what's going on }\end{array}$ & 4.53 & 4.30 \\
$\begin{array}{l}\text { I consider myself well qualified to participate in the issue } \\
\text { of broadband Internet access in our community }\end{array}$ & 4.41 & 5.18 \\
\hline $\begin{array}{l}\text { I feel that I could do as a good a job in advocating for } \\
\text { broadband Internet access as most other people }\end{array}$ & 4.64 & 4.88 \\
\hline
\end{tabular}

* Survey choices: $1=$ strongly disagree, $2=$ disagree, $3=$ somewhat disagree, $4=$ neither disagree nor agree, $5=$ somewhat agree, $6=$ agree, $7=$ strongly agree.

contacting elected officials, trying to persuade others, and working with others to do something about the issue.

\section{Results}

All 142 participants filled out the preforum survey, 90 percent (128) completed the on-site forum experience questionnaire, and 55 percent (78) responded to the follow-up postforum

\section{Table 3. Means for Satisfaction Items from Forum Experience Questionnaire*}

\begin{tabular}{ll}
\hline Satisfaction Item & Mean \\
\hline Mutual respect: & 4.78 \\
The other group members respected my views on the issue we discussed & 1.15 \\
I felt that other group members did not accept me as part of the group & 4.88 \\
Diversity of contribution: & 4.61 \\
Everyone in our group had a chance to express their opinions & 4.34 \\
A variety of opinions were expressed in today's forum & \\
I learned a lot from the discussions & 4.15 \\
Reevaluation: & 3.64 \\
Our group discussion uncovered aspects of the issue I hadn't considered before \\
I'm thinking differently about the issue now that I have participated in the forum \\
Commitment to continued deliberation: & 4.38 \\
I would be willing to work with this group in the future & 4.67 \\
Working with my group was an enjoyable experience & 4.00 \\
Utility of deliberation: & 4.43 \\
I am confident that our discussion will have a positive impact in our community \\
I would recommend using discussion forums like this to address community issues
\end{tabular}

* 5-point Likert scale in which $1=$ strongly disagree, $2=$ somewhat disagree, $3=$ neutral, $4=$ somewhat agree, and $5=$ strongly agree. 
Table 4. Postforum Information Seeking, Follow-Up Discussion, and Advocacy Activities Reported by Participants*

\begin{tabular}{lr}
\hline Topic & Percentage (Frequency) \\
\hline Information seeking: & $45(35)$ \\
Reread the forum discussion guide & $44(34)$ \\
Looked up other information from the Internet & $14(11)$ \\
Looked up the online information guide & $5(4)$ \\
Asked for the printed version of the online information guide & $69(54)$ \\
Follow-up discussion: & $42(33)$ \\
Talked with friends and family about the issue & $38(30)$ \\
Talked with an Internet service provider about the issue & $20(16)$ \\
Talked with community leaders about the issue & $18(14)$ \\
Advocacy: & $8(6)$ \\
Contacted elected officials about the issue & \\
Tried to persuade others to do something about the issue & \\
Worked with others to do something about the issue & \\
\hline
\end{tabular}

* Seventy-eight participants responded to the e-mailed survey, representing a $55 \%$ response rate.

survey. Information seeking during the forum was first investigated by content analysis in the quantity and type of questions asked by participants. Out of 5,233 participant utterances analyzed, over 25 percent $(1,339)$ utterances included questions. Facilitator questions employed to moderate the deliberation were removed from the analysis, leaving 601 participantuttered questions. Of those, the researchers, employing a codebook, identified 56 percent fact questions, 32 percent clarification questions, .06 percent policy questions, .03 percent value questions, and .02 percent rhetorical questions. A further content analysis of 452 fact questions to categorize broadband topics of interest to the participants identified twenty-two topics (see table 5), based on the vocabulary of the utterances. The most-cited topics were broadband distribution, connectivity, funding sources, and cost. These show that participants wanted most to learn about the extent of broadband penetration, the physical means of connectivity, and collective funding or personal costs that pertain to their access. Lower numbers of federal, state, or municipal questions, despite facilitator prompting from the protocol, could indicate that fewer participants were inclined or prepared to examine specific government contributions. The results to question RQ1a offer a topical framework for librarians wishing to organize information on high-speed Internet.

The data from the preforum survey revealed that 44 percent of the participants sought some sort of information about broadband connectivity before the forum. Based on the selfreported data from the follow-up survey, many participants engaged in one or more types of activity after the forums (see table 4). Question RQ1b is answered in the affirmative, with 
Table 5. Categorized Broadband Topics of Conversation by Frequency of Reference

\begin{tabular}{lc}
\hline Topic & Frequency \\
\hline Distribution: geographic extent of broadband & 46 \\
Connectivity: means of broadband access & 39 \\
Funding: funding sources & 34 \\
Cost: consumer costs & 31 \\
Agency: who does what to enable broadband access & 29 \\
Technology: technical means of access & 28 \\
Definitions: of terminology, abbreviations, acronyms & 27 \\
Influence: who influences decision making & 23 \\
Other: nonbroadband topics & 23 \\
ISP: questions about Internet service providers & 22 \\
Libraries: as employers/providers of broadband access & 19 \\
Schools: as users/providers of broadband access & 19 \\
Applications: specific apps or programs & 18 \\
Utilization: uses to which broadband is put & 14 \\
Public/private interaction: roles in providing broadband & 12 \\
Policy: legislation, laws, regulatory procedure & 11 \\
Federal: programs, roles, laws, legislation, regulation & 7 \\
State: programs, roles, laws, legislation, regulation & 5 \\
City: municipal roles, programs, or specific city facts & 4 \\
Products: specific consumer items, such as tablets, phones & 4 \\
Hospitals: as users/providers of broadband access & 3 \\
\hline
\end{tabular}

44 percent and 45 percent of respondents rereading the forum discussion guide and looking up other information from the Internet, though it is instructive that consulting the librarycreated guide either online or in print was reported much less. Question RQ1c can be answered in the affirmative, with the higher reporting of conversations with friends and family, as well as contacts with Internet service providers and community leaders. Although one cannot guess whether those conversations also included information seeking or advocacy elements, it is certain that respondents were seeking out those whose decisions might make a difference to their broadband access situation.

A t-test was conducted to examine the differences in self-efficacy before and after the forum. Table 2 illustrates the changes in self-efficacy for each item. Although most respondents' answers hovered near the neutral center position of the Likert scale, there was a significant increase in participants' self-efficacy after the forum $(t=2.39$, df $=62, p=.02)$. Question RQ2 is answered in the affirmative.

Table 3 shows that means for participant satisfaction were positive for all measures, with highest agreement on elements of mutual respect and diversity of contribution. The only score somewhat closer to neutral was for thinking differently on the issue after the discussion. Question $\mathrm{RQ}_{3}$ is answered in the affirmative. 


\section{Discussion}

The collection of data from Broadband Everywhere forums provided a detailed record of what actually transpired in discussion, augmented by participants' perceptions and actions before and after. Researchers who observed the events and later coded each utterance noted that many participants arrived at the forums expecting "less participation, more information." Transcripts reveal many participants saying that they wanted more information on broadband access before they felt prepared to advocate for it. The following sample of participants' answers to the final forum question is illustrative: "I need to be more informed myself and so I'm happy to have these two things up here, which I will do to find out more information; I would like to become much more knowledgeable about this whole thing, including how it's funded and how do you keep local control; I would learn about the proposals so that when I send an e-mail I'll know maybe what I'm talking about; I think this is a good first step just talking about possibilities, and research that needs to be done, and plans and possible outcomes."

With over half of the original sample responding to the e-mail survey indicating they had followed up on broadband in at least one of three ways, librarians can conclude that further engagement with the issue was stimulated by the participatory event. The highest numbers reported for follow-up discussion with friends and family echoes research findings that informal information seeking among acquaintances or use of networked sources is preferred before consulting print media or organizational sources in everyday problem solving (Savolainen 2008, 290). Small-town librarians need not be discouraged by this, if they can become better acquaintances of their participant/patrons. It is clear that they must play a more active role promoting their own expertise in answering specific broadband questions or in delivering networked information resources that do so.

An unqualified promotion of deliberation as a means of increasing self-efficacy based on this data would be premature, although the positive pattern is encouraging. The literature of political deliberation has offered similar observational studies to this one, but fewer experimental studies using control groups to determine whether lack of deliberation demonstrates reduced internal political self-efficacy.

An experimental study by Michael Morrell (2005) accounted for two factors in the relationship between deliberation and participants' self-efficacy. One is the form of deliberation itself - that is, the purpose, format, and protocol that make up a deliberative program. The other factor is the specified context for the behavior addressed in self-efficacy-for example, "advocating for broadband." His experiments with college students showed that the experience influenced participants' self-efficacy in the practice of deliberation itself. Increased confidence in performing this form of group communication activity can contribute with practice to enhanced political communication skills in other arenas, such as testifying before elected officials or campaigning. In fact, one participant in the broadband project visited 
the state capital to testify before a committee after the forums. A librarian who reported increased self-efficacy through the practice of facilitating multiple broadband forums held a follow-up educational forum in her community with an emphasis on the regulatory and budgetary dimensions of USF.

Reported satisfaction with the broadband forum experience demonstrated success in the organizers' ability to meet deliberative standards of acceptance, equal opportunity, and respect for all participants. The participants' enjoyment of the process of working with one another on the issue, their willingness to do so again with the group or to recommend it to others, and a positive assessment of its impact on their own thinking about the issue all validate the use of the facilitated deliberative forum as a means of civic engagement.

The findings from this study should encourage librarians (whether from school, public, or academic institutions) to engage the public in not only the broadband issue but other important policy subjects by means of deliberative forums. The social nature of public discussion, when proficiently facilitated by a neutral moderator, can stimulate inquiry by individuals and groups to complement other forms of learning, such as public lectures or private reading.

The sequence of facilitator questions in this project offered an exercise in civic learning, moving from inquiry into personal experiences with broadband to more complex community expectations and modes of broadband delivery at local, state, and national levels. In the process of discussion, participants discovered their own information deficits, a common experience in learning although not a goal admitted at many public meetings. Frustrating as that discovery may have been to some, it stimulated in many participants a search for information, exactly the motivation that libraries are organized to promote and assist.

Another finding from this study relates to a common anxiety that "town hall meetings" might serve only to stage an uncivil parade of ideological rivalries. If citizens fear that exploring issues in public discussion exposes them to ridicule, anger, or even violence, then many forms of public assembly are at risk. None of this transpired in this series of broadband discussions, which were conducted according to ground rules of civility discussed and agreed to by participants in the forums (see footnote to table 1). High scores in participant satisfaction on mutual respect attest to the quality of civil discourse that was maintained.

\section{Recommendations}

If exposure of information deficit, investigation of community knowledge, and inquiry beyond the discussion can all be produced in a single forum event, then the promises of libraryhosted public issue forums on complex topics outweigh perceived perils. A single event, however, is only an opening for those few who make time in their schedules to participate. This project underscored the need to expand the experience and frequency of citizen deliberation in order to build community engagement on issues and to influence citizens' self-efficacy. 
Researchers need to seek opportunities to gather data from sequential (rather than singleevent) forums and to examine inclusivity, particularly involvement of normally disenfranchised populations. A succession of three municipal broadband consensus conferences conducted in California (Karpowitz, Raphael, and Hammond 2009) offers an instructive model. Their research focused attention on deliberation by low-income citizens typically absent from policy discussions. They solicited participation in a community panel from groups with the lowest rates of home access to commercial broadband, then provided them with a briefing paper one month before a three-weekend forum series using the Consensus Conference protocol. ${ }^{5}$ The panel produced a report with recommendations to statewide leaders, who testified that participants understood well the basic issues surrounding municipal broadband, not only by their conclusions but by their questions and other comments. Participants demonstrated a high degree of learning over the three-weekend experience and increasing confidence in their ability to offer good recommendations to official policy makers.

Librarians need to work with researchers to ensure an inclusive sample of citizens participating in not one, but a succession, of events to strengthen the impact of deliberative forums. Lack of a more inclusive or representative sample not only has limited the researchers' ability to generalize about what the larger population's connectivity experience has been but it defeats a core purpose of the National Broadband Plan, which is to establish "universal" public service in broadband as well as telephone contexts. To solicit an inclusive sample, librarians need to make special efforts to match the demographic characteristics of their user population as well as solicit representatives of underserved groups. A limitation of this study that was outside of the control of the researchers was that participants choosing to come to the forums were of an older age, higher income, and higher formal education than the surrounding twelve-county average reported in census data. In order to achieve a more representative sample, libraries should evaluate the demographic gaps in turnout and, if necessary, move successive events to venues more accessible to underrepresented groups by partnering with organizations or sites where they routinely gather to talk.

The need for inclusion was demonstrated by 2013 changes to this state's Universal Services Fund that were written into law a year after the forums, which made no reference to the needs of high-cost area, low-income citizens. Instead, the bill contained provisions to circumvent universal service provisions, such as eliminating carrier of last resort obligations of telecommunications companies to low-population, unprofitable areas of the state (Springe 2013).

5. The first weekend was devoted to reviewing the briefing paper, soliciting participant questions for an expert panel, and recommending additional reading. The second weekend featured expert panelists' answers to participants' questions and a first phase of actual deliberation on questions over municipal government investment in broadband access and services to underserved communities. The third weekend was devoted to developing participants' consensus on municipal broadband that was reported in a subsequent forum of statewide municipal leaders, ISPs, and community groups considering municipal broadband projects. 
Citizens need to understand that access to high-speed Internet is essentially an issue of inclusion versus exclusion. Rural populations face the prospect of more digital exclusion in the United States due to the higher costs that carriers incur, extending last-mile broadband to lowdensity markets. Low-income residents in urban areas relying on libraries and other public institutions for their high-speed Internet access need to testify to the impact of the National Broadband Plan on their communities' well-being. According to a federally mandated planning document, Building Digital Communities, the "cost of digital exclusion is great. Without access, full participation in nearly every aspect of American society - from economic success and educational achievement, to positive health outcomes and civic engagement-is compromised" (Institute of Museum and Library Services 2012, 1).

The IMLS framework for guiding public discussion on broadband lists six themes in addition to public access that libraries and citizens need to learn about and advocate for their communities: broadband availability, affordability, design for inclusion, relevance, digital literacy, and consumer safety. Given the centrality of digital inclusion to full citizen participation, the authors recommend that deliberation be employed by libraries in a well-crafted succession of inclusive public forums on each theme, each documented by a consensus report delivered to state decision makers with publicized demands for a response. Deliberation on broadband and other technical issues should be augmented by educational events and libraryprovided resources that promote community learning.

\section{References}

Alita, John. 2001. "Creating an Internet Policy by Civic Engagement." American Libraries 32 (11): 48-50. Bandura, Albert. 1995. Self-Efficacy in Changing Societies. New York: Cambridge University Press.

Bertot, John Carlo, 2006. Public Libraries and the Internet 2006: Study Results and Findings. Tallahassee: Information Use Management and Policy Institute, College of Information, Florida State University. http:// www.ala.org/offices/files/oitp/PDFs/2006_plinternet.pdf.

$\rightarrow$ Bronstein, Jenny, and Lilian Tzivian. 2013. "Perceived Self-Efficacy of Library and Information Science Professionals regarding Their Information Retrieval Skills." Library and Information Science Research 35 (2): 151-58.

Burkhalter, Stephanie, John Gastil, and Todd Kelshaw. 2002. "A Conceptual Definition and Theoretical Model of Public Deliberation in Small Face-to-Face Groups." Communication Theory 12 (4): 398422.

$\rightarrow$ Falch, Morten. 2007. "Penetration of Broadband Services - the Role of Policies." Telematics and Informatics 24 (4): $246-58$.

Federal Communication Commission. 2010. Connecting America: The National Broadband Plan. Washington, DC: Federal Communications Commission. http://www.broadband.gov/plan/.

$\rightarrow$ Gastil, John. 2004. "Adult Civic Education through the National Issues Forums: Developing Democratic Habits and Dispositions through Public Deliberation." Adult Education Quarterly: A Journal of Research and Theory 54 (4): 308-28.

Gastil, John, and Peter Levine, eds. 2005. The Deliberative Democracy Handbook: Strategies for Effective Civic Engagement in the Twenty-First Century. San Francisco: Jossey-Bass. 
Institute of Museum and Library Services. 2012. Building Digital Communities: Getting Started. Washington, DC: Institute of Museum and Library Services. http://www.imls.gov/assets/1/AssetManager/Building DigitalCommunities.pdf.

Jaeger, Paul T., John Carlo Bertot, and Ursula Gorham. 2013. "Wake Up the Nation: Public Libraries, Policy Making, and Political Discourse." Library Quarterly 83 (1): 61-72.

Karpowitz, Christopher F., Chad Raphael, and Allen S. Hammond. 2009. "Deliberative Democracy and Inequality: Two Cheers for Enclave Deliberation among the Disempowered." Politics and Society 37 (4): 576-615.

$\rightarrow$ Kurbanoglu, S. S. 2003. "Self-Efficacy: A Concept Closely Linked to Information Literacy and Lifelong Learning." Journal of Documentation 59 (6): 635-46.

Miller, Warren E. 1989. American National Election Study, 1988: Pre- and Post-election Survey. Ann Arbor, MI: InterUniversity Consortium for Political and Social Research. http://www.icpsr.umich.edu/icpsrweb/ICPSR /studies/9196.

Morrell, Michael. 2005. "Deliberation, Democratic Decision-Making, and Internal Political Efficacy." Political Behavior 27 (1): 49-69.

Morrell, Michael. 2010. Empathy and Democracy: Feeling, Thinking, and Deliberation. University Park: Pennsylvania State University Press.

$\rightarrow$ Niemi, Richard G., Stephen C. Craig, and Franco Mattei. 1991. "Measuring Internal Political Efficacy in the 1988 National Election Study." American Political Science Review 85 (4): 1407-13.

Savolainen, Reijo. 2008. "Source Preferences in the Context of Seeking Problem-Specific Information." Information Processing and Management 44 (1): 274-93.

Schenck-Hamlin, Donna, Carol Barta, and Judy Burgess. 2010. "Kansas Broadband Information for Citizens.” http://guides.lib.k-state.edu/content.php?pid=306395.

Springe, David. 2013. “H.B. 2201 Testimony on Behalf of the Citizens' Utility Ratepayer Board." http://curb .kansas.gov/legislative/2013/HB_2201.pdf.

Stromer-Galley, Jennifer, and Peter Muhlberger. 2009. "Agreement and Disagreement in Group Deliberation: Effects on Deliberation Satisfaction, Future Engagement, and Decision Legitimacy." Political Communication 26 (2): 173-92.

US Department of Commerce. 2013. Exploring the Digital Nation: America's Emerging Online Experience. http:// www.ntia.doc.gov/files/ntia/publications/exploring_the_digital_nation_-_americas_emerging _online_experience.pdf.

Donna Schenck-Hamlin: undergraduate and community specialist at Kansas State Libraries and library associate at the Institute for Civic Discourse and Democracy (ICDD), Kansas State University. Schenck-Hamlin facilitates public forums using protocols for dialogue and deliberation including Deliberative Polling, Appreciative Inquiry, and National Issues Forums. Her work with ICDD focuses on deliberative democracy theories and practices and with Kansas State Libraries on the facilitation of public inquiry. E-mail (corresponding author): donnash@k-state.edu.

Soo-Hye Han: assistant professor of communication studies and research associate at the Institute for Civic Discourse and Democracy (ICDD) at Kansas State University. Han's research focuses on how people come to understand their roles as citizens through political discourse and mass media. Her research has appeared in American Behavioral Scientist, Electronic Journal of Communication, 
and Communication Teacher. She teaches undergraduate and graduate courses in political communication, communication theory, and research methods. E-mail: soohye@k-state.edu.

Bill Schenck-Hamlin: professor of communication studies and associate at the Institute for Civic Discourse and Democracy (ICDD), Kansas State University. Schenck-Hamlin's work can be found in journals such as Communication Monographs, Human Communication Research, Communication Quarterly, Western Journal of Communication, Women and Politics, Journalism Quarterly, Argumentation and Advocacy, and the Journal of Social Psychology. He is currently exploring the role of persuasion and argument quality in citizen deliberations of political and social issues. E-mail: billsh @k-state.edu. 